\title{
High resolution observations of turbulence in the troposphere and lower stratosphere over Gadanki
}

\author{
G. Dutta ${ }^{1}$, M. C. Ajay Kumar ${ }^{2}$, P. Vinay Kumar ${ }^{1}$, P. V. Rao ${ }^{3}$, B. Bapiraju ${ }^{4}$, and H. Aleem Basha ${ }^{1}$ \\ ${ }^{1}$ Department of Physics, Anwarul-Uloom College, New Mallepally, Hyderabad, India \\ ${ }^{2}$ Department of Physics, Vanjari Seethaiah Memorial College of Engg., Bandlaguda, Hyderabad, India \\ ${ }^{3}$ Department of Physics, Vasavi College of Engg., Ibrahimbagh, Hyderabad, India \\ ${ }^{4}$ Department of Physics, A. V. College, Domalguda, Hyderabad, India
}

Received: 7 November 2007 - Revised: 3 June 2009 - Accepted: 3 June 2009 - Published: 11 June 2009

\begin{abstract}
High resolution (150 m) wind measurements from 13-17 July 2004 by Mesosphere-Stratosphere-Troposphere (MST) radar and 15-16 July 2004 by Lower Atmospheric Wind Profiler (LAWP) have been used to study the time variation of turbulence intensity. Layers of higher turbulence are observed in the lower stratosphere on 15-16 July which give rise to mixing in the region. Enhancement in short-period gravity wave activity and turbulent layers are observed after 22:00 LT which could be due to a dry convection event that occurred at that time. The breakdown of the convectively generated high frequency waves seems to have given rise to the turbulence layers. Wind shear is found to be high above the easterly jet, but very poor correlation is observed between square of wind shear and turbulence parameters in the region. The heights of the turbulent layers in the lower stratosphere do not correlate with levels of minimum Richardson number. A monochromatic inertia gravity wave could be identified during 13-17 July 2004. A non-linear interaction between the waves of different scales as proposed by Hines (1992) might also be responsible for the breakdown and generation of turbulence layers.
\end{abstract}

Keywords. Meteorology and atmospheric dynamics (Convective processes; Middle atmosphere dynamics; Turbulence)

\section{Introduction}

The general circulation of the middle atmosphere is known to be strongly influenced by the transport of momentum by different kinds of wave motions with different spatial

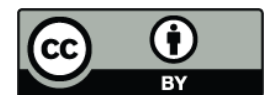

Correspondence to: G. Dutta (gopadutta@yahoo.com) and temporal scales. Turbulence and gravity waves belong to these important types of atmospheric motions at micro and mesoscales. Turbulence diffuses whereas gravity waves propagate. Gravity waves generated due to boundarylayer convection, jet-stream passages or flow over mountainous terrains grow in amplitudes while propagating upwards to conserve momentum as the atmospheric density decreases. Eventually they become unstable, induce instability and break into turbulence. Convective clouds are also an important source of turbulence (Pantley and Lester, 1990). There are various mechanisms responsible for generation of turbulence including convectively generated gravity waves and their subsequent breakdown (Lane et al., 2001). A wave can break and generate turbulence at a critical level due to wave-wave interaction (Pavelin et al., 2002). The mechanism of wave scavenging, proposed by Hines (1992), discusses wave breaking in the light of interaction of waves with smaller and larger wavelengths. Hines's theory recognizes a natural transition from linear source spectra at lower altitudes to a non-linear saturated spectrum at higher altitudes. However, several numerical studies have undermined assumptions of Hines's theory (Eckermann, 1997; Walterscheid, 2000). But Fritts and Alexander (2003) pointed out that wave-wave interactions are important in exchange of energy among gravity waves of various scales throughout the middle atmosphere. The understanding of the turbulence generation mechanisms are a topic of current research.

Turbulence, so generated by various methods, has important effects on atmospheric chemistry, mixing air of different composition and stratosphere-troposphere exchange. VHF radars can measure wind velocity and turbulence intensity reliably up to an altitude of about $20 \mathrm{~km}$ using the backscattered radar echoes from small-scale variations of temperature and humidity (Gage, 1990). Röttger (1980) explained the echoing mechanism to be due to turbulent scatter and Fresnel reflection. Balsley et al. (1983) interpreted it in terms

Published by Copernicus Publications on behalf of the European Geosciences Union. 

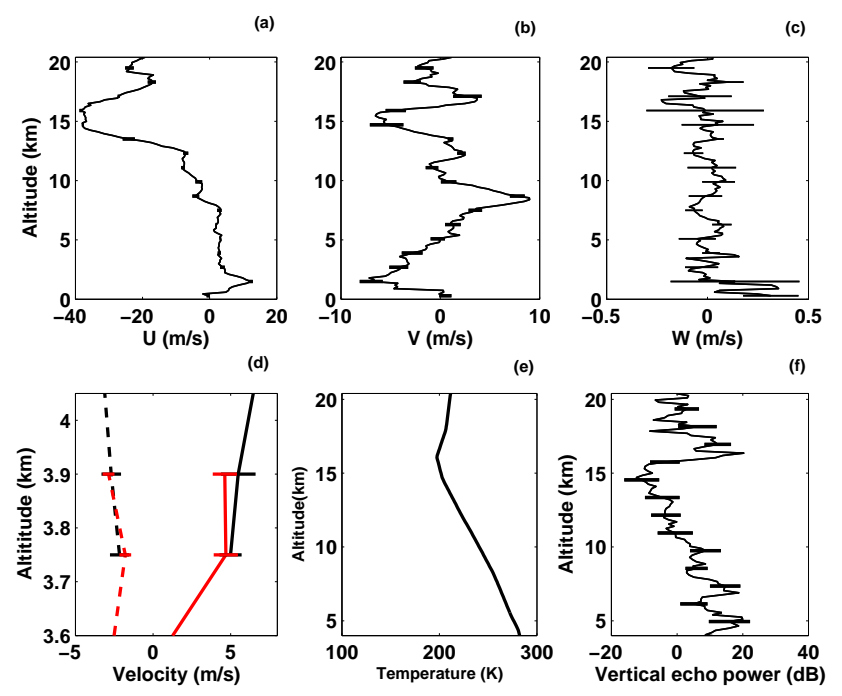

Fig. 1. One hour averaged sample profiles of zonal (a), meridional (b) and vertical (c) winds measured by LAWP and MST radar between 13:00-14:00 LT. Comparisons of zonal (solid) and meridional (dashed) winds measured by LAWP (red) and MST radar (black) for two overlapping heights (d). Temperature profile over Chennai (e) and vertical beam echo power measured by MST radar (averaged between 13:00-14:00 LT) (f).

of breakdown of tides and gravity waves which indicates that the turbulence generation by breaking of waves could be responsible for the echoes. Muraoka et al. (1988) reported Fresnel scattering to be a dominant mechanism in the lower stratosphere and Hines (1992) extended Muraoka's analysis to offer an alternative interpretation in terms of non-linear wave-wave interaction.

We report here MST radar observations of turbulent layers in the lower stratosphere after 22:00 LT (16:30 UTC) on 15-16 July 2004 over a tropical site Gadanki. An Inertia Gravity Wave (IGW) is also found to be prevailing between 13-17 July over the same station. An effort has been made to interpret the layers with known mechanisms. It is worth mentioning here that the observation of turbulence layers and examining different mechanisms to explain them using high resolution radar data of Gadanki is the first of its kind.

\section{Observations}

The VHF radar at Gadanki operates at a frequency of $\sim 53 \mathrm{MHz}$ in coherent backscatter mode with an average power-aperture product of $7 \times 10^{8} \mathrm{~W} \mathrm{~m}^{2}$. It generates radiation pattern with one way beam width of $3^{\circ}$ and can be steered between $\pm 20^{\circ}$ from the zenith. A detailed description of the radar is given by Rao et al. (1995). The vertical and horizontal wind data obtained from the radar continuously for $24 \mathrm{~h}$ in five beam directions (one zenith beam and four $10^{\circ}$ off-zenith beams in the North, East, South and West

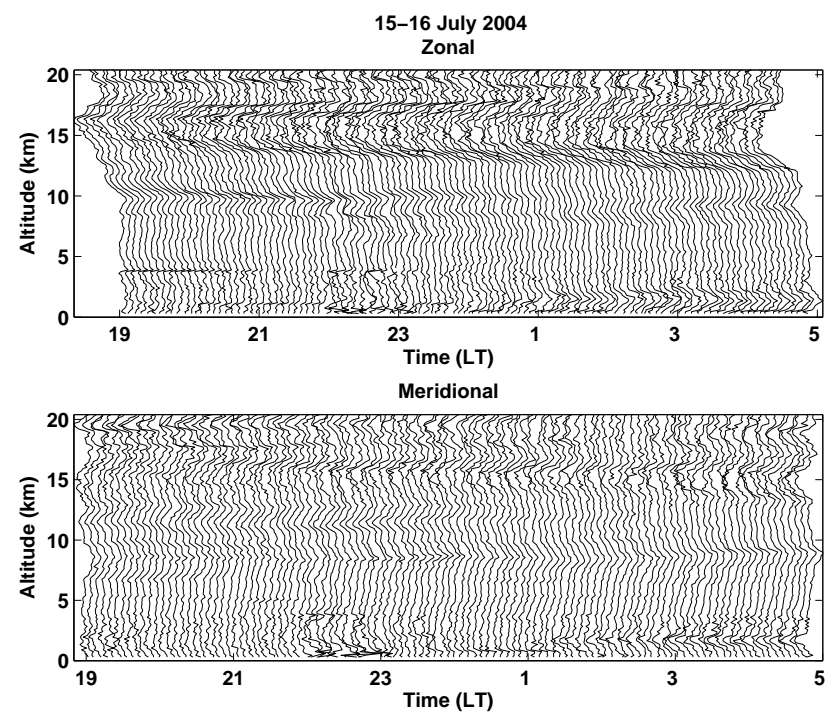

Fig. 2. Profiles of zonal (a) and meridional (b) winds shifted by $5 \mathrm{~m} / \mathrm{s}$, measured by MST radar and LAWP averaged over $5 \mathrm{~min}(2$ profiles) between 19:00 and 04:55 LT.

directions) on 15-16 July 2004 with a height resolution of $150 \mathrm{~m}$ and a time resolution of $\sim 2.5 \mathrm{~min}$ have been used for this study which revealed generation of turbulence layers in the lower stratosphere after 22:00 LT. Height profiles of wind velocities between 3.75 and $20.4 \mathrm{~km}$ were subjected to stringent data processing, both on-line and off-line (Dutta et al., 1999). Outliers were removed by taking mean wind in 3-h section for each height and discarding values exceeding 1.7 times the standard deviation. Such gaps, which were found to be very rare, were filled up by interpolation. The LAWP installed at the same facility by National Institute of Information and Communications Technology (NICT), Japan (formerly known as CRL) provided wind data of 15-16 July 2004 between the altitudes of $500 \mathrm{~m}$ to $6 \mathrm{~km}$ with a height resolution of $150 \mathrm{~m}$ and a time resolution of $2 \mathrm{~min}$. The radar with an operating frequency of $1357.5 \mathrm{MHz}$ uses a fixed sequence of three beam directions in cyclic manner: $15^{\circ}$ due North, $15^{\circ}$ due East and Zenith. The beam width of the radar is $4^{\circ}$ with a gain of $39 \mathrm{~dB}$ and an effective power aperture product of $1.2 \times 10^{4} \mathrm{~W} \mathrm{~m}^{2}$. Various features of the radar are given by Reddy et al. (2001). Since the MST radar and LAWP are designed for upper level and lower level winds respectively, the matching of the wind data in the overlap region was checked by plotting $1 \mathrm{~h}$ averaged wind data between 13:00-14:00 LT estimated by both the radars. LAWP data were accepted below $3.6 \mathrm{~km}$ and averages of MST and LAWP data were taken for two heights 3.75 and $3.9 \mathrm{~km}$ for continuity. Figure 1a, b and c show the sample wind profiles measured by both the radars with standard deviations at a few heights. Figure 1d shows LAWP and MST radar measured zonal (solid) and meridional (dashed) winds at two overlapping heights with error bars. Since the uncertainty 


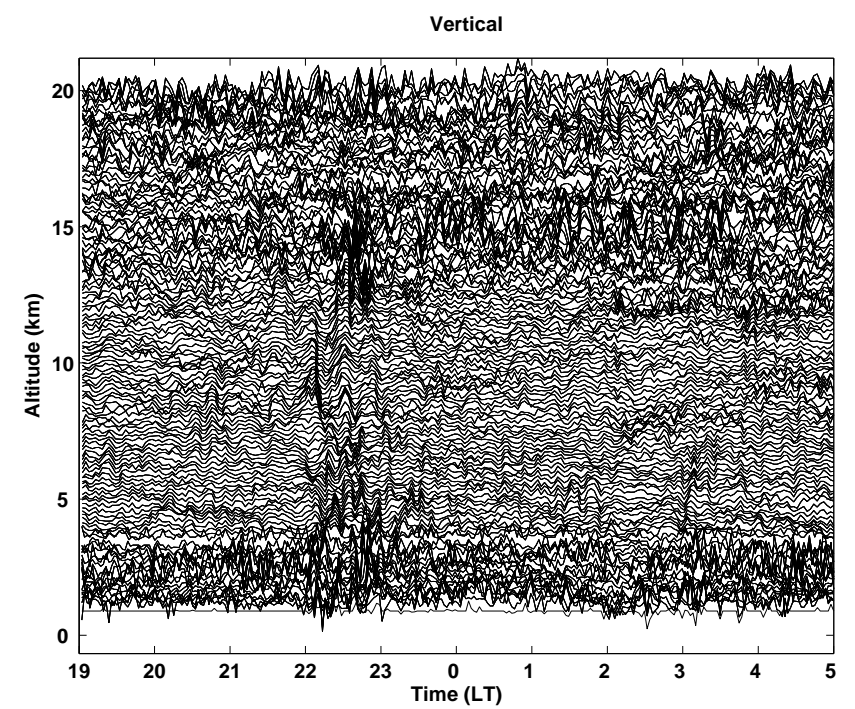

Fig. 3. Time series of vertical winds shifted by $0.15 \mathrm{~m} / \mathrm{s}$ for the same time interval.

bars overlap, the results from both the radars agree. There was no rainfall during the observation period. Temperature and humidity data of 15 July are taken from the 17:30 LT Chennai radiosonde flight which is $\sim 120 \mathrm{~km}$ away from the radar station. Relative humidity was sufficiently high (82$83 \%$ ) between 5 and $6 \mathrm{~km}$. The cold point tropopause is at an altitude of $16.1 \mathrm{~km}$. Figure 1e and $\mathrm{f}$ show temperature profile over Chennai and vertical beam echo power (average from 17:00-19:00 LT) measured by MST radar respectively. The higher stability of the stratosphere gives enhancement of echo power above the tropopause (Vaughan et al., 1995). The altitude (16-16.3 km) where the echo power is seen to increase, agrees well with the radiosonde detected tropopause height.

Wind data collected by MST radar starting at 02:00 LT on 13 July and ending at 18:00 LT on 17 July 2004 with intervals of $\sim 1-2 \mathrm{~h}$ have also been used to study prevailing inertia gravity wave activity during the period.

\section{Results and discussion}

\subsection{Short-period wind oscillation}

Profiles of zonal $(u)$ and meridional $(v)$ winds measured by MST radar and averaged over $5 \mathrm{~min}$ ( 2 profiles) between 19:00 and 04:55 LT on 15-16 July are depicted in Fig. 2a, $\mathrm{b}$ which have been shifted by appropriate intervals as mentioned in the caption. A strong easterly jet $\left(-36 \mathrm{~m} \mathrm{~s}^{-1}\right)$ is observed throughout the day. The jet velocity started becoming stronger around 22:00 LT and persisted for about $5 \mathrm{~h}$ when it reached $-43 \mathrm{~m} \mathrm{~s}^{-1}$. Various waves with different vertical scales are exhibited in zonal and meridional wind profiles. Longer period wind oscillations can be seen be-
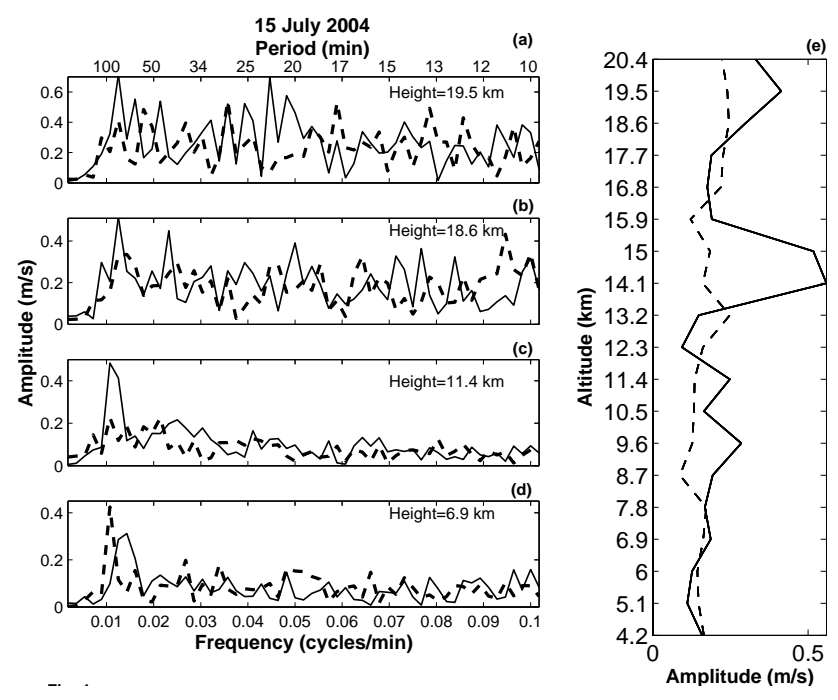

Fig. 4. Frequency spectra of short-period zonal (solid) and meridional (dashed) wind fluctuations at a few heights (a, b, c, d). Height profiles of zonal (solid) and meridional (dashed) amplitudes of $<2 \mathrm{~h}$ oscillation (e).

low about $13 \mathrm{~km}$ whereas shorter period waves are prominent above this height. Figure 3 illustrates vertically shifted time series of vertical velocities $(w)$ for the same time interval (19:00 to 04:55 LT). The time variation of " $w$ " clearly shows short period wind fluctuations in the lower stratosphere. Disturbances in vertical wind are enhanced $\left(\sim 1 \mathrm{~m} \mathrm{~s}^{-1}\right)$ after 22:00 LT throughout the observation region.

This high resolution wind data of $9 \mathrm{~h} 55 \mathrm{~min}$ (between 19:00 to 04:55 LT) have been averaged over $900 \mathrm{~m}$ altitude blocks, high-pass filtered to retain wind oscillations with less than $2 \mathrm{~h}$ period and subjected to FFT analyses. Short-period waves between $60-100 \mathrm{~min}$ are prominent throughout the altitude range and the periodicities with $<60 \mathrm{~min}$ are observed to be significant in the lower stratosphere. The FFT results are illustrated in Fig. 4a, b, c, d. The amplitude height profiles of 60-100 min waves (Fig. 4e) show high zonal amplitudes below the tropopause $\left(\sim 0.5 \mathrm{~m} \mathrm{~s}^{-1}\right)$ and in the lower stratosphere $\left(\sim 0.4 \mathrm{~m} \mathrm{~s}^{-1}\right)$. The meridional amplitudes are less $\left(\sim 0.2 \mathrm{~m} \mathrm{~s}^{-1}\right)$.

July is the month of south-west monsoon with strong easterly jet and frequent cumulus convection. We have, therefore, examined the high resolution hourly cloud top equivalent blackbody temperature, called Brightness Temperature (BT) which can be used as a proxy for tropical deep convection. The data recorded by MTSAT-1R (Multi-functional Transport SATellite) have been provided by the Japan Meteorological Agency (JMA) through Kochi University, Japan in the longitude-latitude grids of $0.05^{\circ}$. TBB data between $11^{\circ} \mathrm{N}-15^{\circ} \mathrm{N}$ latitude and $77^{\circ} \mathrm{E}-81^{\circ} \mathrm{E}$ longitude covering the location of Gadanki for a few hours around 22:00 LT are illustrated in Fig. 5 which clearly show low values of TBB over Gadanki at 22:00 LT and convective activity in surrounding 

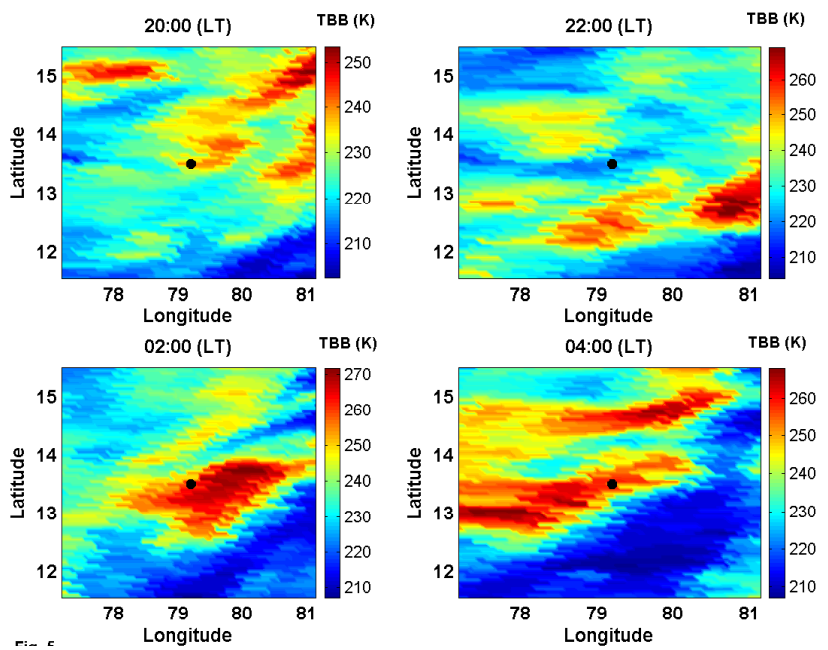

Fig. 5. Latitude-longitude distribution of the satellite brightness temperature (TBB) observed on 15-16 July 2004, for a few hours around 22:00 LT.

area for several hours. Since there was no rainfall on $15-$ 16 July, it appears to be a dry convection event at 22:00 LT which might have generated short period gravity waves locally. Observations of high frequency waves in the stratosphere have shown a close correspondence with convective clouds (Sato et al., 1995; McLandress et al., 2000; Alexander et al., 2000). Our observations are similar to the events previously reported at the EAR in Indonesia (Dhaka et al., 2005; Yamamoto et al., 2007).

\subsection{Inertia gravity wave oscillation}

Zonal and meridional wind data between 13-17 July 2004 have been spline-interpolated for every $3 \mathrm{~h}$ and the appropriately shifted profiles from $3.75 \mathrm{~km}$ to $20.4 \mathrm{~km}$ are shown in Fig. 6. Downward phase propagation can be clearly identified particularly in zonal winds below $15 \mathrm{~km}$. The time series of wind velocities averaged over $900 \mathrm{~m}$ height blocks have been detrended and band-pass filtered between 48-66 h periods. The fluctuations, so obtained have been subjected to FFT analyses. The FFT spectra of zonal and meridional wind fluctuations at four heights are depicted in Fig. 7a, b, c, $\mathrm{d}$ which show the presence of monochromatic inertia gravity wave of period $\sim 54 \mathrm{~h}$ (the inertial period at Gadanki is $53.34 \mathrm{~h})$. The time-series $(108 \mathrm{~h})$ of zonal and meridional wind fluctuations have been subjected to least square analysis to estimate the amplitudes of $54 \mathrm{~h}$ oscillations and the amplitude-height profiles of zonal and meridional winds are shown in Fig. 7e. Large zonal wind amplitude of $\sim 5 \mathrm{~m} \mathrm{~s}^{-1}$ is observed near $11 \mathrm{~km}$ altitude.

Hodograph analysis has been carried out to obtain some important parameters of inertia gravity waves. A few hodographs of the horizontal wind vector in stratosphere and troposphere are shown in Fig. 8. Some important parame-
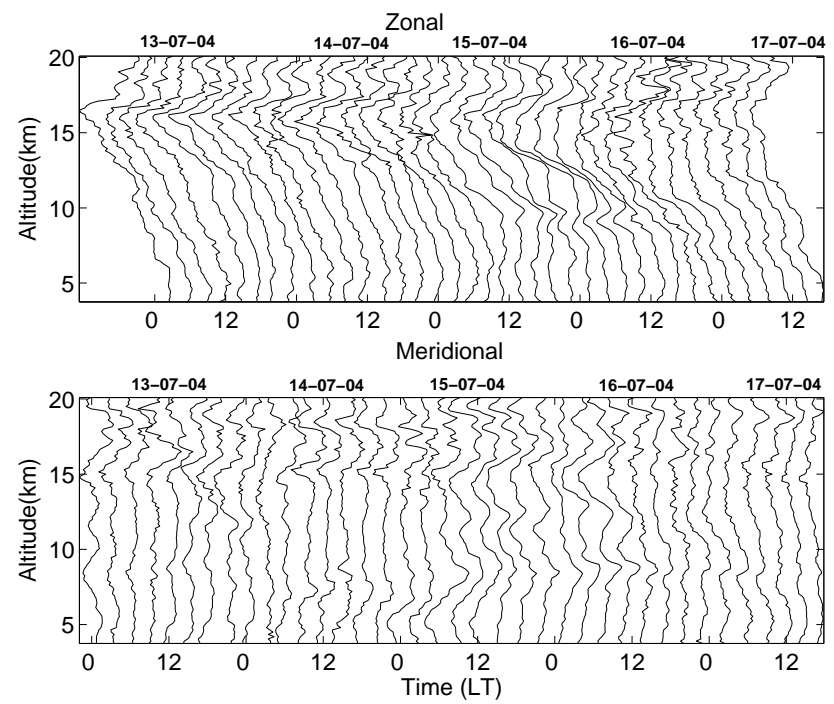

Fig. 6. Profiles of zonal (a) and meridional (b) winds shifted by 9 and $10 \mathrm{~m} / \mathrm{s}$, measured by MST radar during 13-17 July 2004 which have been shifted by $10 \mathrm{~m} / \mathrm{s}$.

ters of inertia gravity wave have been delineated following Cho (1995). The analysis shows mostly clockwise rotation of the wind vector in the lower stratosphere which means upward energy propagation. Hodographs in the upper troposphere do not give a very clear picture with almost equal number showing clockwise (12) and anti-clockwise (9) rotations whereas those in the lower troposphere show predominantly anti-clockwise rotation. So the source of the observed inertia gravity waves cannot be clearly indentified. Sasi et al. (2000) had similar observations and suggested that the easterly jet present during summer monsoon could be the source of IGW. The high-resolution numerical simulation, by Mahalov et al. (2007) showed the generation of inertia gravity waves from the jet stream at the tropopause. Niranjan and Ramkumar (2008) have reported the generation of inertia gravity waves by depression caused during south-west monsoon over the Indian sub-continent. The occurrence of inertia gravity waves, in the tropics, has been frequently linked to convection as the source (Karoly et al., 1996; Shimizu and Tsuda, 1997; Vincent and Alexander, 2000). Since the present study has been undertaken in the month of July, the observed inertia gravity wave could have been the result of jet stream and/or convection in the surrounding area. Some estimated wave parameters are listed in Table 1 which are found to have close agreements with earlier reports for the same site (Sasi et al., 2000; Niranjan and Ramkumar, 2008).

\subsection{Turbulence layers in the lower stratosphere}

Atmospheric turbulence causes random fluctuations of various atmospheric parameters. High resolution VHF radars are excellent tools to make measurements of refractivity 
Table 1. IGW parameters over Gadanki.

\begin{tabular}{lcc}
\hline Parameter & $\begin{array}{c}7.65-10.35 \mathrm{~km} \\
\text { altitude region }\end{array}$ & $\begin{array}{c}18.0-20.4 \mathrm{~km} \\
\text { altitude region }\end{array}$ \\
\hline Ratio of minor to major axis & 0.40 & 0.26 \\
Intrinsic period (hours) & 20 & 13 \\
Vertical wavelength $(\mathrm{km})$ & 2.5 & 1.5 \\
Horizontal wavelength $(\mathrm{km})$ & 250 & 130 \\
Vertical group velocity $\left(\mathrm{cm} \mathrm{s}^{-1}\right)$ & 4.7 & 0.81 \\
Horizontal group velocity $\left(\mathrm{m} \mathrm{s}^{-1}\right)$ & 2.6 & 2.1 \\
Vertical phase velocity $\left(\mathrm{cm} \mathrm{s}^{-1}\right)$ & 3.1 & 1.4 \\
Horizontal phase velocity $\left(\mathrm{m} \mathrm{s}^{-1}\right)$ & 3.4 & 2.5 \\
\hline
\end{tabular}

structure constant $\left(C_{n}^{2}\right)$, echo power etc. The turbulence refractivity structure constant $\left(C_{n}^{2}\right)$ is one of the basic parameters of atmospheric turbulence and can be determined by using the radar measurements of the received radar echo intensity (VanZandt et al., 1978; Hocking et al., 1989, Ghosh et al., 2001, Rao et al., 1997, 2001). The refractivity structure constant $\left(C_{n}^{2}\right)$ is proportional to radar volume reflectivity $(\eta)$ and is given by:

$\eta=\frac{32(\ln 2) K_{B} B_{N}\left(\alpha_{r} T_{C}+T_{r}\right)}{P_{t} \alpha_{r} \alpha_{t} A_{e} \Delta r N_{B} N_{c}}\left(\frac{r}{\Delta r}\right)^{2}\left(\frac{S}{N}\right)$

where $(S / N)$ is SNR for oblique beams, $P_{t}$ is the peak transmitted power, $A_{e}$ is effective antenna area, $\alpha_{r}$ is receiver path loss, $\alpha_{t}$ is the transmitter path loss, $N_{B}$ is the number of bauds for coded pulse, $N_{C}$ is number of coherent integration, $T_{c}$ is cosmic noise temperature, $T_{r}$ is receiver noise temperature, $K_{B}$ is the Boltzman's constant, $B_{N}$ is effective receiver band width, $\Delta r$ is the range resolution and $r$ is the range of back scatter echo.

The turbulent refractivity structure constant $C_{n}^{2}$ is related to the radar volume reflectivity as:

$\eta=(0.38) C_{n}^{2} \lambda^{-1 / 3}$

where $\lambda$ is the radar wavelength.

A contour of $C_{n}^{2}$ for 15-16 July between 19:00 LT04:55 LT in the altitude range of $15-20 \mathrm{~km}$ is shown in Fig. 9a. A specular echo effect was avoided by using SNR data from oblique beams only (Hocking, 1985). The averaged data of oblique beams also helps to neglect horizontal anisotropy (Nastrom and Tsuda, 2001). The echo intensity measured by MST radar is another very important parameter signifying turbulence. The echoing mechanisms could be due to turbulent scatter and Fresnel reflection (Lindzen, 1981; Röttger and Liu, 1978), breakdown of tides and gravity waves (Balsley et al., 1983) and wave-wave interaction (Hines, 1992). It has also been reported that the enhanced echo is associated with a maximum shear generated by waves which may lead to dynamical instability (Yamamoto et al., 1987). The contour of echo power for 15-16 July observations is shown in Fig. 9b for the same interval of time and
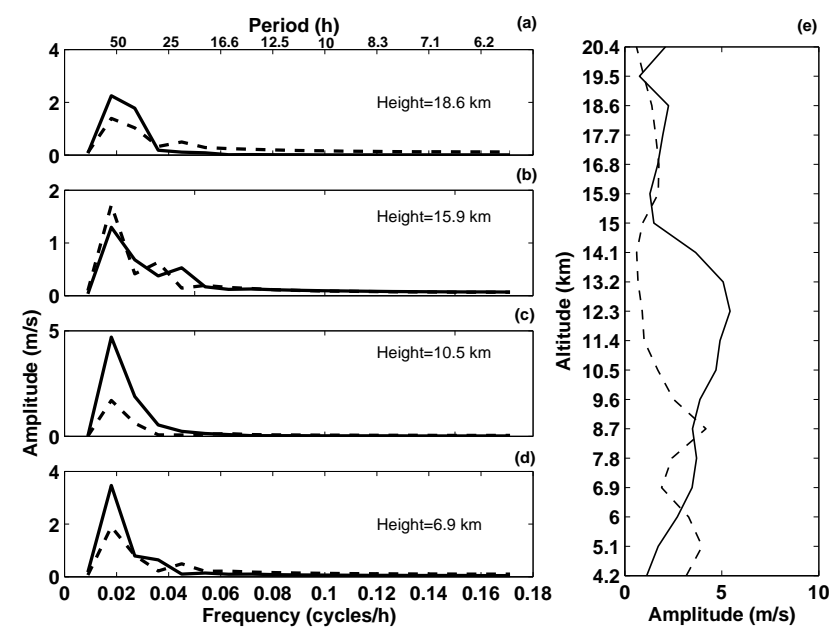

Fig. 7. Same as Fig. 4, but for long period (48-66h) wind fluctuations.

altitude. Both these figures show turbulence layers in the lower stratosphere at $\sim 19-20 \mathrm{~km}$ after 22:00 LT.

Vertical wind variance is a measure of gravity wave activity and the short-period variance is found to be associated with local convection (Dutta et al., 2008). Vertical wind variance of $<2 \mathrm{~h}$ gravity waves for 15-16 July have been computed using both LAWP and MST data and Fig. 9c shows its temporal variation between 19:00 LT-04:55 LT. Enhancement of short-period gravity wave activity can be noticed after 22:00 LT below the tropopause at $\sim 15-16 \mathrm{~km}$.

Disturbances in wind velocities are observed after 22:00 LT with simultaneous enhancements in turbulence parameters. There are a number of mechanisms that may be responsible for the generation of turbulence. Vertical shear in horizontal wind is known to give rise to turbulence where Richardson number $\left(R_{i}\right)$ is $<0.25$. The profiles of $R_{i}$, square of wind shear and potential temperature from $10-15 \mathrm{~km}$ are shown in Fig. 10. Strong layers of wind shear are observed below and above the tropopause due to the presence of jet stream. The corresponding value of $R_{i} \approx 0.9$. Inhomogeneous shear stratified turbulence is supposed to be relevant for the real atmosphere (Mahalov et al., 2007). Layers of turbulence can be seen in the lower stratosphere where wind shear is significant. But correlation studies between square of wind shear and the turbulent parameters in the lower stratosphere show poor correlation suggesting that dynamic instability may not be the reason of observed turbulence layers.

Numerical simulation study by Lane et al. (2001) showed the generation of gravity waves due to convection and their subsequent breakdown. The present study also points to generation of short-period gravity waves due to local convection after 22:00 LT. The turbulence layers in the lower stratosphere appear to be mostly due to the breakdown of these waves. Large scale, low frequency inertia gravity wave of $\sim 54 \mathrm{~h}$ period is also found to be present during the 

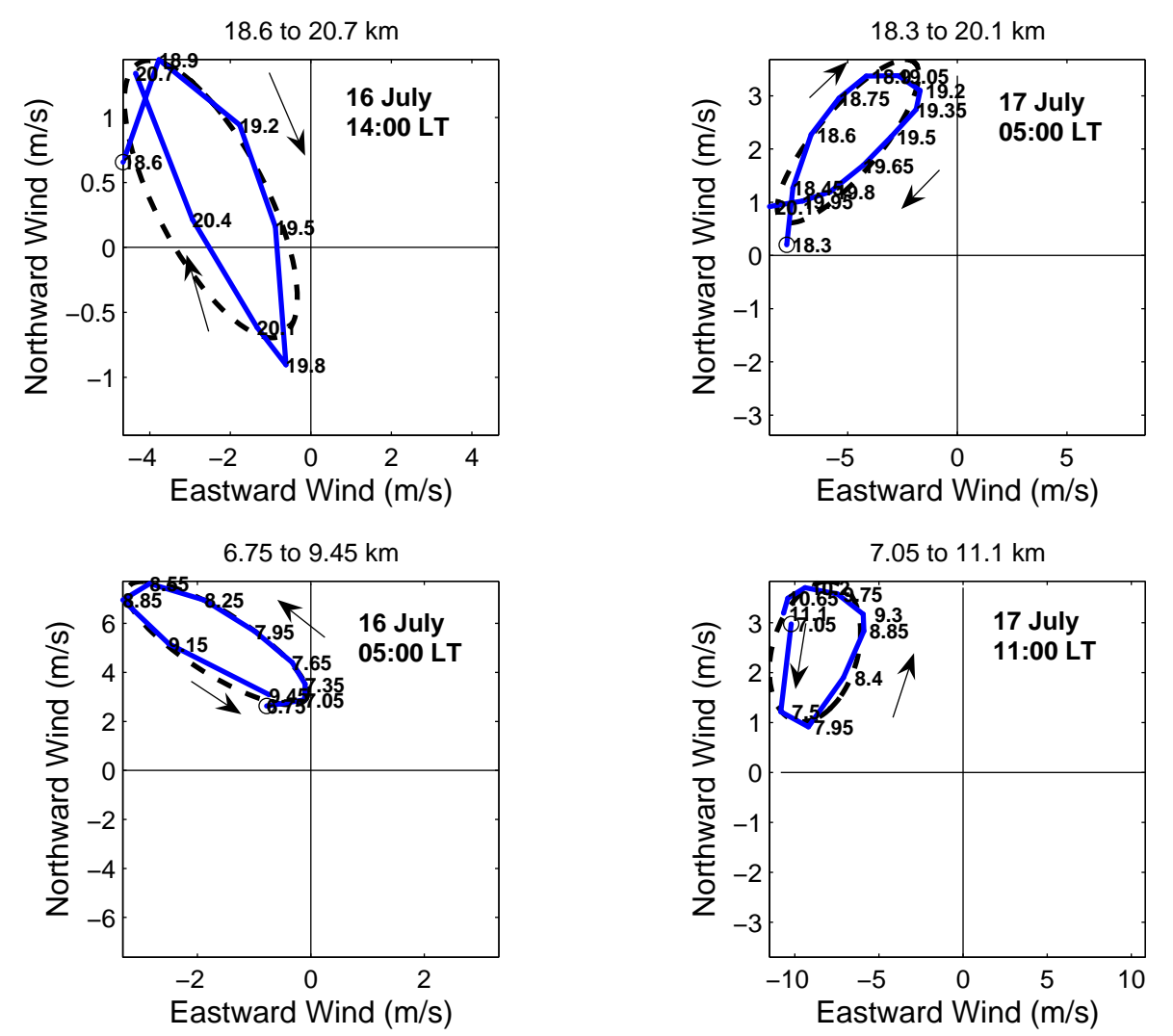

Fig. 8. Hodographs of the horizontal wind fluctuations in stratosphere and troposphere. The lowest height is marked by solid circle and the direction of rotation is indicated by arrows.

observation period. The non-linear interaction between the high frequency and low frequency waves could also result in the wave breaking and generation of turbulence layers.

Hines (1992) has proposed wave scavenging as a possible mechanism of wave breaking where waves with smaller wavelengths break at critical levels that occur because of the induced wind perturbations due to the waves with larger wavelengths. Hines (1968) and Hines (1991) stressed that strong shears in large scale winds could act to scavenge energy for turbulence from a particularly broad spectrum of small-scale waves and produce turbulence. This interpretation has been tested by drawing critical circles following Hines (1992). Hodograms of $7 \mathrm{~h}$ winds between 22:00 and 04:55 LT (shown in Fig. 11) have provided the centers of successive critical circles between the altitudes of 15.9 and $20.4 \mathrm{~km}$. The areas enclosed by the arcs represent wave scavenging over corresponding height intervals. Significant scavenging is seen above $15.9 \mathrm{~km}$ with waves propagating in the NW and NE quadrants. The scavenging area disappears at $16.32 \mathrm{~km}$ and resurfaces again above $16.65 \mathrm{~km}$. Scavenging increases considerably above $17.7 \mathrm{~km}$ and swings to mostly SE quadrant disappearing at $17.85 \mathrm{~km}$. Small scavenging can again be observed between 18.15 and $18.9 \mathrm{~km}$. Large scavenging is seen above this height at $19.2 \mathrm{~km}$. Correlation of the enhanced layers of $C_{n}^{2}$ and echo power can be seen with high scavenging potential for the corresponding heights as already mentioned.

\section{Summary}

Turbulence near the tropopause plays a major role in mixing chemical constituents of the upper troposphere and lower stratosphere. The rate of mixing depends on the amount of turbulence which influences chemical reaction between different species. An accurate understanding of turbulence is thus very essential. We have made high resolution observations of MST radar and LAWP to study the time evolution of turbulence for a summer day. Layers of turbulence are seen in the lower stratosphere after 22:00 LT. TBB plots show the presence of higher local convection around the same time over Gadanki and also in surrounding areas for a couple of hours. Short-period gravity wave activity also gets enhanced between 22:00 and 04:55 LT. It is likely that the high frequency convectively generated gravity waves breakdown and give rise to the observed turbulence layers.

A monochromatic inertia gravity wave has also been identified during the observation period (13-17 July). The mechanism of critical layer scavenging of gravity wave energy to 

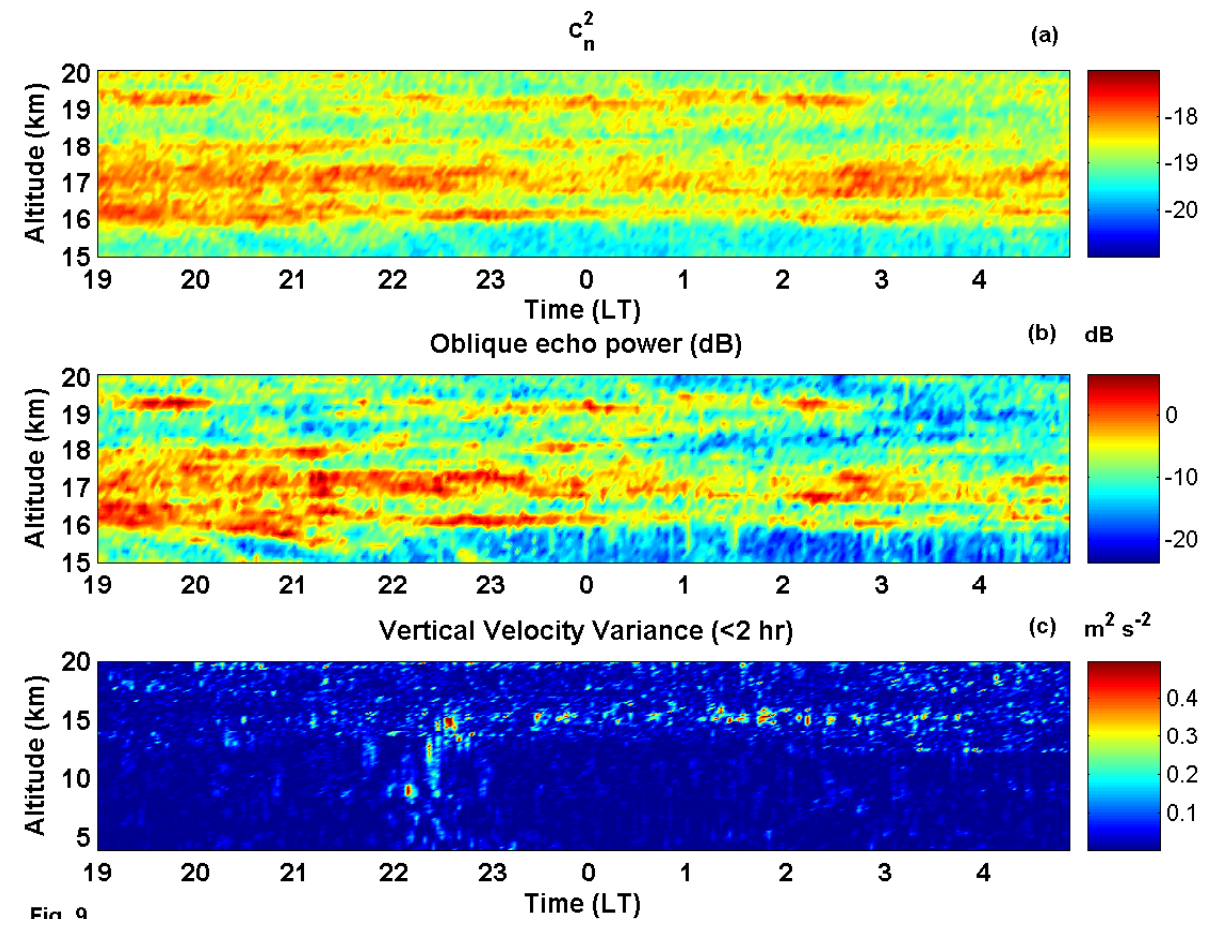

Fig. 9. Contours of $C_{n}^{2}$ (a) and echo power (b) between 15 and $20 \mathrm{~km}$ for $\sim 10 \mathrm{~h}$ from 19:00-04:55 LT. Short-period vertical wind variance for the altitude range from $500 \mathrm{~m}-20 \mathrm{~km}$ and for the same interval of time (c).
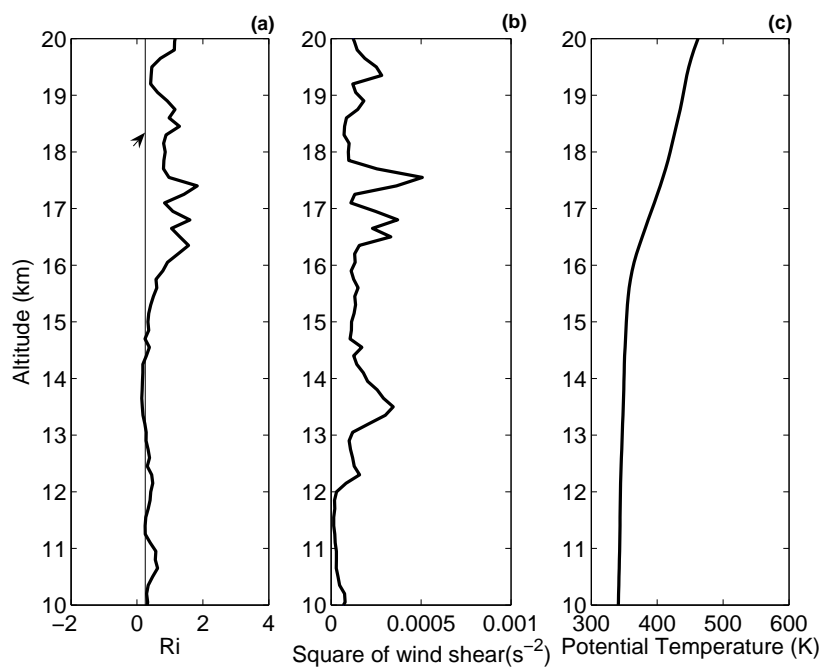

Fig. 10. Height profiles of Richardson number, square of vertical shear in horizontal wind (averaged over 19:00-04:55 LT) and potential temperature from $10-20 \mathrm{~km}$.

produce turbulence has been tested following Hines (1992). It is likely that the non-linear interaction between the waves of different scales might also be responsible for the observed turbulence layers. However, it should be noted that different mechanisms of wave breaking can coexist together and complement each other.

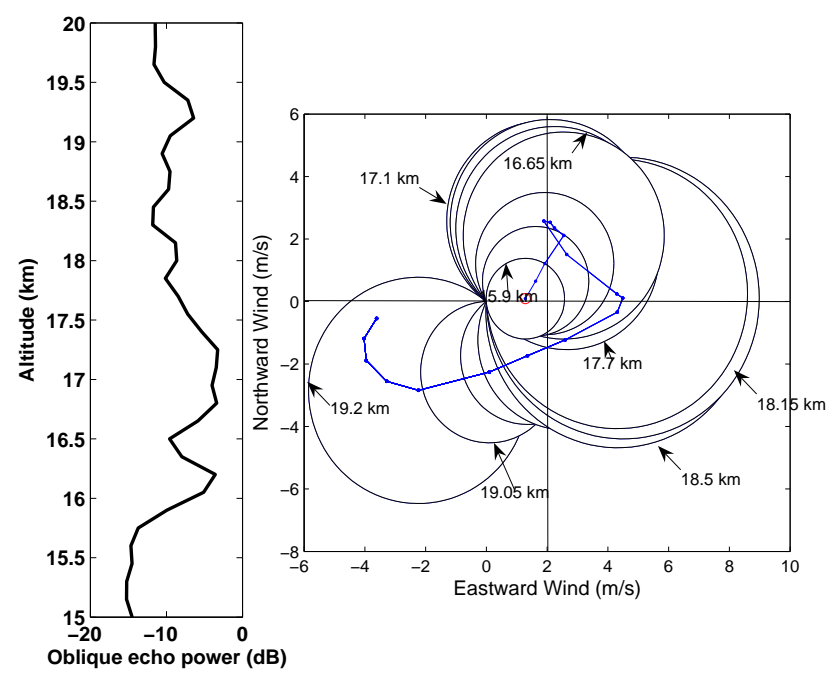

Fig. 11. Hodogram of winds to provide centers of critical circles and critical circles for different heights to identify regions of potentially strong scavenging.

Acknowledgements. The Indian MST radar project was funded jointly by DOE, DOS, DOEn, DST, DRDO, and CSIR, with DOS as the nodal agency. The authors are grateful to Department of Science and Technology, Government of India, for providing financial assistance to run the project. The authors also wish to thank UGC-SVU Center for MST Radar Applications, S. V. University, 
for providing necessary facilities to carry out the research work. High resolution TBB data provided by Y. Shibagaki (Osaka Electro - Communication University, Japan) and M. Venkat Ratnam (National Atmospheric Research Laboratory, India) are gratefully acknowledged. The authors would like to thank the staff of NARL for their kind support. Helpful comments by the anonymous reviewers which substantially improved the quality of the paper are warmly acknowledged. The authors are also thankful to the management of Anwarul-Uloom College for their kind encouragement.

Topical Editor U.-P. Hoppe thanks two anonymous referees for their help in evaluating this paper.

\section{References}

Alexander, M. J., Beres, J. H., and Pfister, L.: Tropical stratospheric gravity wave activity and relationship to clouds, J. Geophys. Res., 105, 22299-22309, 2000.

Balsley, B. B., Ecklund, W. L., and Fritts, D. C.: VHF echoes from the high-latitude mesosphere and lower thermosphere: observations and interpretation, J. Atmos. Sci., 40, 2451-2466, 1983.

Cho, J. Y. N.: Inertia-gravity wave parameter estimation from crossspectral analysis, J. Geophys. Res., 100, 18727-18737, 1995.

Dhaka, S. K., Yamamoto, M. K., Shibagaki, Y., Hashiguchi, H., and Yamamoto, M.: Convection-induced gravity waves observed by the Equatorial Atmosphere Radar $\left(0.20^{\circ} \mathrm{S}\right.$, $\left.100.32^{\circ} \mathrm{E}\right)$ in Indonesia, Geophys. Res. Lett., 32, L14820, doi:10.1029/2005GL022907, 2005.

Dutta, G., Bapiraju, B., Balasubrahmanyam, P., and Aleem Basha, H.: VHF radar observations of gravity waves at a low latitude, Ann. Geophys., 17, 1012-1019, 1999, http://www.ann-geophys.net/17/1012/1999/.

Dutta, G., Tsuda, T., Kumar, P. V., Kumar, M. C. A., Alexander, S. P., and Kozu, T.: Seasonal variation of short-period $(<2 \mathrm{~h})$ gravity wave activity over Gadanki, India $\left(13.5^{\circ} \mathrm{N}, 79.2^{\circ} \mathrm{E}\right), \mathrm{J}$. Geophys. Res., 113, D14103, doi:10.1029/2007JD009178, 2008.

Eckermann, S. D.: Influence of wave propagation on the Dopplerspreading of atmospheric gravity waves, J. Atmos. Sci., 54, 2554-2573, 1997.

Fritts, D. C. and Alexander, M. J.: Gravity wave dynamics and effects in the middle atmosphere, Rev. Geophys., 41, 1/1003, doi:10/1029/2001RG000106, 2003.

Gage, K. S.: Radar observations of the free atmosphere Structure and dynamics. Radar in Meteorology, American Meteorological Society, Chapter 28a, 1990.

Ghosh, A. K., Siva Kumar, V., Kishore Kumar, K., and Jain, A. R.: VHF radar observation of atmospheric winds, associated shears and $C_{n}^{2}$ at a tropical location: interdependence and seasonal pattern, Ann. Geophys., 19, 965-973, 2001, http://www.ann-geophys.net/19/965/2001/.

Hines, C. O.: Mesospheric VHF echoing layers; an interpretation of certain observations in terms of wave scavenging, J. Atmos. Terr. Phys., 54, 1043-1049, 1992.

Hines, C. O.: Some consequences of gravity-wave critical layers in the upper atmosphere, J. Atmos. Terr. Phys., 30, 837-843, 1968.

Hines, C. O.: The saturation of gravity waves in the middle atmosphere III; formation of the turbopause and of turbulent layers beneath it, J. Atmos. Sci., 48, 1380-1386, 1991.

Hocking, W. K., Lawry, K., and Neudegg, D.: Radar measurements of atmospheric turbulence intensities by $C_{n}^{2}$ and spectral width method, Middle Atmospheric program Hand Book, 27, 443-446, SCOSTEP Secretariat Univ. Illinois, 1989.

Hocking, W. K.: Measurement of turbulent energy dissipation rates in the middle atmosphere by radar techniques; A review, Radio Sci., 20, 1403-1422, 1985.

Karoly, D. J., Roff, G. L., and Reeder, M. J.: Gravity wave activity associated with tropical convection detected in TOGA COARE sounding data, Geophys. Res. Lett., 23, 261-264, 1996.

Lane, T. P., Reeder, M. J., and Clark, T. L.: Numerical modeling of gravity wave generation by deep tropical convection, J. Atmos. Sci., 58, 1249-1274, 2001.

Lindzen, R. S.: Turbulence and stress owing to gravity wave and tidal breakdown, J. Geophys. Res., 86, 9707-9714, 1981.

McLandress, C., Alexander, M. J., and Wu, D. L.: Microwave LINK sounder observations of gravity waves in the stratosphere: A climatology and interpretation, J. Geophys. Res., 105, 1194711967, 2000.

Muraoka, Y., Sugiyama, T., Kawahira, K., Sato, T., Tsuda, T., Fukao, S., and Kato, S.: Cause of monochromatic inertia-gravity wave breaking observed by the MU radar, Geophys. Res. Lett., 15, 1349-1352, 1988.

Mahalov, A., Moustaoui, M., Nicolaenko, B., and Tse, K. L.: Computational studies of inertia-gravity waves radiated from upper Tropospheric jets, Theor. Comput. Fluid Dyn., 21, 399-422, doi:10.1007/s00162-007-0062-1, 2007.

Nastrom, G. D. and Tsuda, T.: Anisotropy of Doppler spectral parameters in the VHF radar observations at MU and White Sands, Radio Sci., 19, 883-888, 2001.

Niranjan Kumar, K. and Ramkumar, R. K.: Characteristics of inertia-gravity waves over Gadanki during the passage of a deep depression over the Bay of Bengal, Geophys. Res. Lett., 35, L13804, doi:10.1029/2008GL033937, 2008.

Pantley, K. C. and Lester, P. F.: Observations of severe turbulence near thunderstorm tops, J. Appl. Meteor., 29, 1171-1179, 1990.

Pavelin, E. G. and Whiteway, J.: Gravity wave interactions around the jet stream, Geophys. Res. Lett., 29(21), 2024, doi:10.1029/2002GL015783, 2002.

Rao, D. N., Kishore, P., Rao, T. N., Rao, S. V. B., Reddy, K. K., Yarraiah, M., and Hareesh, M.: Studies on refractivity structure constant, eddy dissipation rate, and momentum flux at a tropical latitude, Radio Sci., 32, 1375-1389, 1997.

Rao, D. N., Rao, T. N., Venkataratnam, M., Thulisiraman, S., Rao, S. V. B., Srinivasulu, P., and Rao, P. B.: Diurnal and seasonal variabilities of turbulent parameters observed with Indian mesosphere-stratosphere-troposphere radar, Radio Sci., 36(6), 1439-1457, 2001.

Rao, P. B., Jain, A. R., Kishore, P., Balamuralidhar, P., Damle, S. H., and Viswanthan, G.: Indian MST radar, 1, system description and sample vector wind measurements in ST mode, Radio Sci., 30, 1125-1138, 1995.

Reddy, K. K., Kozu, T., Ohno, Y., Nakamura, K.,Srinivasula, P., Anandan, V. K., Jain, A. R., Rao, P. B., Ranga Rao, R., Viswanthan, G., and Rao, D. N.: Lower atmosphericwind profiler at Gadanki, Tropical India: initial result, Meterologische Zeitschrift., 10, 457-466, 2001.

Röttger, J. and Liu, C. H.: Partial reflection and scattering of VHF radar signals from clear atmosphere, Geophys. Res. Lett., 5, 357360, 1978.

Röttger, J.: Structure and dynamics of the stratosphere and meso- 
sphere revealed by VHF radar investigation, Pageoph, 118, 494527, 1980.

Sasi, M. N., Geetha Ramkumar., Deepa, V., and Krishna Murthy, B. V.: Inertia-gravity waves associated with the tropical easterly jet over the Indian subcontinent during the south west monsoon period, Geophys. Res. Lett., 27(19), 3201-3204, 2000.

Sato, K., Hashiguchi, H., and Fukao, S.: Gravity waves and turbulence associated with cumulus convection observed with the UHF/VHF clear-air Doppler radars, J. Geophys. Res., 100(D4), 7111-7119, 1995.

Shimzu, A. and Tsuda, T.: Characteristics of Kelvin waves and gravity waves observed with radiosondes over Indonesia, J. Geophys. Res., 102, 26159-26171, doi:10.1029/96JD03146, 1997.

Van Zandt, T. E., Green, J. L., Gage, K. S., and Clark, W. L.: Vertical profiles of refractivity turbulence structure constant: Comparison of observations by the Sunset Radar with a new theoretical model, Radio Sci., 13, 819-829, 1978.

Vaughan, G., Howells, A., and Price, J. D.: Use of MST radars to probe the mesoscales structures of the tropopause, Tellus, 47A, 759-765, 1995.
Vincent, R. A. and Alexander, M. J..: Gravity waves in the tropical lower stratosphere: An observational study of seasonal and interannual variability, J. Geophys. Res., 105, 17971-17982, 2000.

Walterscheid, R. L.: Propagation of small-scale gravity waves through large-scale internal wave fields: Eikonal effects at lowfrequency approximation critical levels, J. Geophys. Res., 105, 18027-18037, 2000.

Yamamoto, M., Tsuda, T., Kato, S., Sato, T., and Fukao, S.: A saturated inertia gravity wave in the mesosphere observed by the middle and upper atmosphere radar, J. Geophys. Res., 92, 11993-11999, 1987.

Yamamoto, M. K., Nishi, N., Horinouchi, T., Niwano, M., and Fukao, S.: Vertical wind observation in the tropical upper troposphere by VHF wind profiler: A case study, Radio Sci., 42, RS3005, doi:10.1029/2006RS003538, 2007. 